The widespread use of internal prostheses at the hip and elsewhere emphasises the need for more knowledge of human biomechanics and the basic design of prostheses in accordance with the stresses that they have to bear. In the meantime we will inevitably continue to have the occasional breakage of metallic implants.

Links are being forged with the engineering profession. Examples are seen in the Biological Engineering Society, medical sections within the great Institutions of Mechanical Engineers and of Electrical Engineers, a Chair of Biomechanics at the University of Strathclyde in Glasgow, and so forth, and now a coordinating body, the United Kingdom Liaison Committee for Sciences Allied to Medicine and Biology. Cooperative programmes of work are in progress in such places as Norwich, Stanmore, Wrightington, Edinburgh, Glasgow, Imperial College, Hendon, Roehampton, Liverpool and Manchester.

We congratulate Mr Heywood-Waddington on his objectivity and $\mathrm{Mr}$ McKee and his team on their enterprise based on biomechanical concepts. H. Jackson BURRows.

\title{
MEASURING AND RECORDING JOINT MOVEMENT
}

There is still much variation in the method of recording the range of movement of joints. There are not only differences between different centres but even between individuals in the same centre. Consequently, records can be confusing and ambiguous-especially so if a succession of readings in one patient must be made by different individuals. What applies to private and hospital records applies even more to publications and communications.

The American Academy of Orthopaedic Surgeons has promoted order out of chaos by its publication Joint Motion: Method of Measuring and Recording. This was the outcome of the labours of a committee set up in 1959, whose proposals were circulated in a trial pamphlet sent out to members of the Academy and of the American Orthopaedic Association, and to the other English-speaking orthopaedic associations. At a joint meeting of representatives of all these bodies in 1964, in Vancouver, a revised version was agreed. We can look forward therefore to the use of a uniform method throughout the English-speaking world.

Matching its enterprise by its generosity, the Academy has allowed the British Orthopaedic Association to publish a reprint, which has been sent to every Fellow, Member and Associate. The British Association of Physical Medicine is similarly distributing copies, and the Ministry of Health is actively encouraging their use throughout the National Health Service.

Thus we have to thank our American friends for yet another contribution to the advance of medicine and to international collaboration. 